\title{
The contribution of chemokines and migration to the induction of central tolerance in the thymus
}

\author{
Zicheng $\mathrm{Hu}^{\dagger}$, Jessica Naomi Lancaster ${ }^{\dagger}$ and Lauren I. R. Ehrlich* \\ Ehrlich Laboratory, Department of Molecular Biosciences, Institute for Cellular and Molecular Biology, The University of Texas \\ at Austin, Austin, TX, USA
}

\section{OPEN ACCESS}

Edited by:

Geraldo Aleixo Passos,

University of São Paulo, Brazil

Reviewed by:

Monika R. Fleshner,

University of Colorado, USA

Masaaki Murakami,

Hokkaido University, Japan

*Correspondence:

Lauren I. R. Ehrlich,

Ehrlich Laboratory,

Department of Molecular Biosciences, Institute for Cellular and Molecular Biology, The University of Texas at Austin, 2506 Speedway, A5000,

Austin, TX 78712, USA

lehrlich@austin.utexas.edu

${ }^{\dagger}$ Zicheng Hu and Jessica Naomi Lancaster have contributed equally to this work.

Specialty section:

This article was submitted to Immunological Tolerance, a section of the journal Frontiers in Immunology

Received: 04 June 2015

Accepted: 20 July 2015

Published: 07 August 2015

Citation:

Hu Z, Lancaster JN and Ehrlich LIR

(2015) The contribution of chemokines and migration to the induction of central tolerance in the thymus.

Front. Immunol. 6:398. doi: 10.3389/fimmu.2015.00398
As T cells develop, they migrate throughout the thymus where they undergo essential bi-directional signaling with stromal cells in distinct thymic microenvironments. Immature thymocyte progenitors are located in the thymic cortex. Following $T$ cell receptor expression and positive selection, thymocytes undergo a dramatic transition: they become rapidly motile and relocate to the thymic medulla. Antigen-presenting cells (APCs) within the cortex and medulla display peptides derived from a wide array of self-proteins, which promote thymocyte self-tolerance. If a thymocyte is auto-reactive against such antigens, it undergoes either negative selection, via apoptosis, or differentiation into the regulatory $T$ cell lineage. This induction of central tolerance is critical for prevention of autoimmunity. Chemokines and adhesion molecules play an essential role in tolerance induction, as they promote migration of developing thymocytes through the different thymic microenvironments and enhance interactions with APCs displaying self-antigens. Herein, we review the contribution of chemokines and other regulators of thymocyte localization and motility to $T$ cell development, with a focus on their contribution to the induction of central tolerance.

Keywords: thymus, negative selection, central tolerance, chemokine receptors, thymocyte migration

\section{Introduction: Coordination of T Cell Development with Intrathymic Localization}

Thymocytes migrate through distinct thymic microenvironments at discrete stages of differentiation in order to receive essential signals from surrounding stromal cells that govern further differentiation and selection $(1,2)$ (Figure 1). Early thymocyte progenitors (ETP) localize to the cortical side of the cortico-medullary junction (CMJ). As they commit to the T-lineage, thymocytes migrate into the mid-cortex, where they rearrange T cell receptor (TCR) $\beta$ chain genes (3). Cells that successfully express TCR $\beta$ pass the $\beta$-selection checkpoint, and undergo proliferation and differentiation near the sub-capsule. Subsequent double positive (DP) thymocytes are localized throughout the cortex, where they rearrange TCR $\alpha$ chain genes. DP cells that receive weak TCR signals in the cortex undergo positive selection, promoting survival and differentiation of self-MHC-restricted single positive (SP) cells. SP thymocytes migrate into the medulla, where auto-reactive cells receiving strong TCR signals are culled from the repertoire or diverted into the regulatory $\mathrm{T}$ cell (Treg) lineage. We will review migratory and adhesion cues governing localization and cellular interactions of differentiating thymocytes and stromal cell subsets, with an emphasis on signals that promote central tolerance. Recent advances and open questions will be highlighted. 


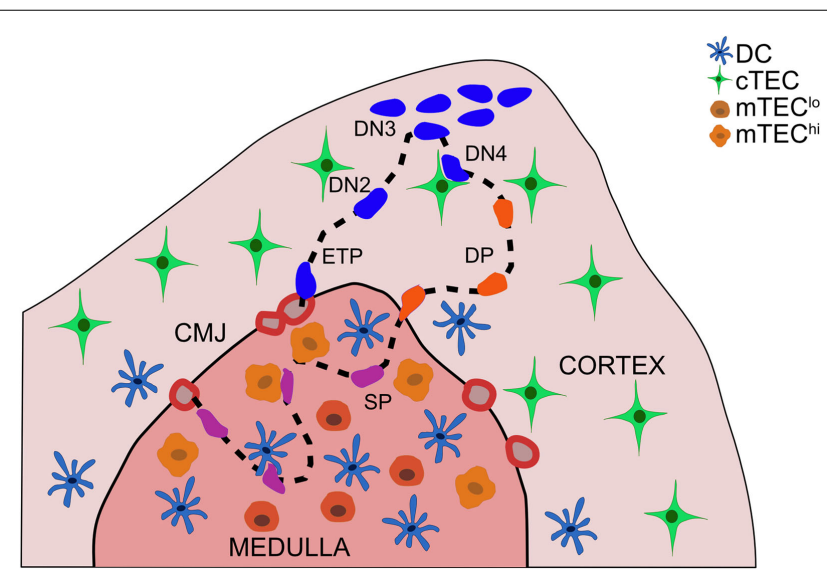

FIGURE 1 | Thymocyte migration through distinct thymic microenvironments occurs in an ordered fashion, enabling appropriate interactions with stromal cells. Thymocyte progenitors enter the thymus through vessels at the cortico-medullary junction (CMJ). ETPs $\left(\mathrm{CD} 3^{-} \mathrm{CD}^{-}{ }^{-} \mathrm{CD}^{-}{ }^{-} \mathrm{C}^{-} \mathrm{Kit}^{+} \mathrm{CD} 44^{+}{ }^{+} \mathrm{CD} 25^{-}\right)$integrate $\mathrm{CTEC}$-derived signals in the cortex near the $\mathrm{CMJ}$, which promote survival and T-lineage-commitment. DN2 $\left(\mathrm{CD}{ }^{-}{ }^{-} \mathrm{CD} 4^{-} \mathrm{CD}^{-}{ }^{-} \mathrm{C}-\mathrm{Kit}^{+} \mathrm{CD}_{4}{ }^{+}{ }^{+} \mathrm{CD} 25^{+}\right)$thymocytes migrate into the mid-cortex, as they rearrange TCR $\beta$ chain genes. Subsequent DN3 $\left(\mathrm{CD} 3^{-} \mathrm{CD}^{-}{ }^{-} \mathrm{CD}^{-}{ }^{-} \mathrm{C}^{-} \mathrm{Kit}^{-} \mathrm{CD}^{-} 4^{-} \mathrm{CD}^{-} 5^{+}\right)$thymocytes that pass the $\beta$-selection checkpoint proliferate at the sub-capsule, and differentiate through a DN4 $\left(\mathrm{CD} 3^{-} \mathrm{CD} 4^{-} \mathrm{CD} 8^{-} \mathrm{C}^{-} \mathrm{Kit}^{-} \mathrm{CD} 44^{-} \mathrm{CD} 25^{-}\right)$stage to become $\mathrm{DP}\left(\mathrm{CD} 4^{+} \mathrm{CD} 8^{+}\right)$thymocytes. DP cells, which rearrange TCR $\alpha$ chain genes, are localized throughout the cortex, with a bias toward the medulla. Interactions with cTECs induce positive selection of DP cells expressing TCRs with low avidity for self-peptide:MHCs. Auto-reactive DP thymocytes can be negatively selected in the cortex. Positively selected DP cells begin to migrate rapidly and enter the thymic medulla, guided by chemokine gradients, as they differentiate into SP thymocytes. SP cells rapidly scan mTECs and DCs during their 4-5-day residence time in the medulla to encounter a wide array of self-peptides, which induce auto-reactive cells to undergo apoptosis or diversion into the Treg lineage. Mature SP thymocytes egress from the thymus through blood vessels in the CMJ.

\section{Migration and Stromal Interactions During Early Stages of Thymocyte Differentiation}

Common lymphoid progenitors or their immediate progeny enter the thymus through vasculature at the CMJ (4), and subsequently give rise to developing $\mathrm{T}$ cells (5-7). Transmigration through the endothelium is initiated by selectin-mediated rolling (P-selectin), followed by firm adhesion via integrins ( $\alpha 4 \beta 1$ and $\alpha \mathrm{L} \beta 2$ ) in concert with chemokine receptor signaling (CCR9, CCR7) (8-12). Within the thymus, cortical thymic epithelial cells (cTECs) provide IL7, SCF, and DLL4, which are indispensable for survival, differentiation, and T-lineage-commitment of thymocyte progenitors (13-15). ETP and double negative 2 (DN2) cells express CXCR4, which promotes chemotaxis toward cTECderived CXCL12 (16-20). Cortical thymocytes also express integrin $\alpha 4 \beta 1$, which binds VCAM-1 on cTECs. CXCR4 deficiency or impaired VCAM-1 adhesion inhibits thymocyte differentiation and migration from the CMJ to the mid-cortex (20-23). It remains to be determined how CCR7 promotes both thymic entry of progenitors into the cortex, and medullary accumulation of SP thymocytes (see below). As ETP do not express CCR7, rapid downregulation of CCR7 following thymic entry may enable cortical progenitor localization.

\section{Migration and Stromal Interactions of Thymocytes Undergoing $\beta$-Selection}

DN3 cells completing TCR $\beta$ rearrangements localize to the outer capsule (4). In addition to pre-TCR signals, activation of CXCR4 (24), NOTCH-1 $(13,25)$, and IL7R via cTEC ligands $(1,26)$ are required for differentiation and expansion at the $\beta$ selection checkpoint. The consequences of or signals governing sub-capsular localization of proliferating post- $\beta$ selection cells remain to be elucidated (3). CCR9 is first expressed at the DN3 stage, and DN3 through DP thymocytes migrate toward CCL25, expressed by cTECs $(17,18,27)$. Deficiency or overexpression of CCR9 prevents DN3 accumulation at the sub-capsule $(12,28$, 29). However, a role for CCR9 in sub-capsular localization is hard to reconcile with the distribution of CCL25 throughout the cortex (30) or the CCR9-responsiveness of DP cells, which are also present throughout the cortex $(17,18)$. Moreover, we have shown that pre-positive selection DP thymocytes, which are CCR9 responsive, accumulate near the medulla, not the sub-capsule (31). Thus, signals governing DN3 accumulation at the sub-capsule remain to be identified.

\section{Migratory Cues Governing Localization and Stromal Interactions of DP Thymocytes}

We speculate that plexinD1 may promote rapid motility and perimedullary accumulation of pre-positive selection DP cells (31). Sema3e, a soluble plexinD1 ligand produced in the medulla, inhibits CCR9-mediated chemotaxis, releases integrin $\alpha 4 \beta 1$ catch bonds, and is required for medullary localization of postpositive selection thymocytes (32-34). However, pre-positive selection DP cells also express plexinD1; thus, DP cells that reach the peri-medullary cortex, perhaps through random migration (35), would encounter Sema3e, potentially diminishing CCR9mediated migration back into the cortex, and relaxing adhesion to VCAM-1 on CTECs, thus increasing motility. Recent studies demonstrate that GIT2, which modulates actin reorganization during cellular migration, also promotes rapid migration of cortical thymocytes (36). GIT2 and plexinD1 may coordinately enhance the ability of DP cells to efficiently scan cTECs for positively selecting ligands, which is consistent with the impaired positive selection in Git2 ${ }^{-/-}$mice (36). Future studies may resolve the roles of plexinD1 and GIT2 in localization, migration, and positive selection of pre-positive selection DP thymocytes.

\section{Migratory Cues and APCs Governing Cortical Negative Selection}

Although the medulla is a critical environment for negative selection, there is mounting evidence that the cortex promotes deletion of a significant number of auto-reactive thymocytes. Thymocytes undergoing negative selection were recently quantified using $\mathrm{Bim}^{-1-}$; Nur77 $7^{\mathrm{GFP}}$ mice (37), in which apoptotic cells survive due to deficiency in the $\mathrm{Bcl} 2$ family 
member Bim, and GFP levels reflect TCR signal strength, enabling quantification of cells that should have been deleted due to strong TCR signaling. In the absence of Bim, $\mathrm{GFP}^{+} \mathrm{DP}$ and $\mathrm{GFP}^{+} \mathrm{SP}$ cellularity was increased, demonstrating that negative selection occurs in both compartments. Interestingly, the increase in $\mathrm{GFP}^{+}$DP cells was up to threefold higher than $\mathrm{GFP}^{+}$SPs (37), suggesting that over $90 \%$ of positively selected DP thymocytes are fated for cortical deletion (38). Another study analyzed Helios levels in $\mathrm{Bim}^{-1-}$ mice to estimate that $55 \%$ of TCR-signaled thymocytes are deleted at the DP stage (39). Together, these studies indicate that the majority of negative selection occurs in DP cells, raising the question of which cortical antigen-presenting cells (APCs) promote central tolerance.

Cortical thymic epithelial cells are uniquely responsible for inducing positive selection (40); however, their role in negative selection remains ambiguous. Early studies established that thymic grafts transplanted into allogeneic athymic hosts were tolerated by host-derived $\mathrm{T}$ cells (41-45). Developing $\mathrm{T}$ cells are likely tolerized to graft-derived peptide:MHCs expressed by medullary TECs (mTECs) or DCs, which does not clarify whether cTECs induce negative selection. To address this, transgenic mice were developed in which MHC-I (46) or MHCII (47) was expressed exclusively on cTECs. cTECs in these mice induced positive selection of CD8SP or CD4SP thymocytes, respectively, but could not tolerize polyclonal thymocytes. In light of the essential contribution of mTECs to negative selection against diverse self-antigens (see below), these findings do not resolve whether cTECs induce deletion of some auto-reactive clones. Expression of model antigens uniquely in cTECs resulted in deletion of TCR transgenic thymocytes, indicating that cTECs can mediate negative selection (48). However, when a TCR transgene was more faithfully expressed at the later DP stage in the $\mathrm{HY}^{\mathrm{CD} 4}$ model, cTECs expressing the cognate antigen induced TCR activation, but not apoptosis of auto-reactive DP cells (49). Thus, cTECs can clearly activate auto-reactive TCRs, but their ability to mediate deletion remains uncertain.

DCs have emerged as likely mediators of cortical negative selection. DCs express high levels of costimulatory and MHC molecules, enabling strong TCR activation (50). Strikingly, in a model of cortical negative selection, thymocytes undergoing apoptosis were localized adjacent to cortical DCs, and negative selection was impaired when DCs were conditionally ablated (49). The migratory cues that promote thymocyte:DC interactions during cortical negative selection have yet to be elucidated. Cortical DCs accumulate near vasculature, where CCR7 ligands are presented $(30,51,52)$. Thymic DCs undergo CCR7-mediated chemotaxis (53), suggesting CCR7 may position DCs near cortical blood vessels. CCR7 was also postulated to induce cortical thymocytes to associate with DCs under positively selecting conditions (52). However, CCR7 is not up-regulated until the SP stage (54), when thymocytes home to the medulla, and CCR7 was dispensable for cortical deletion in the HYcd4 model (49). Thus, CCR7 signaling may position cortical DCs near vasculature, but is unlikely to promote thymocyte:DC interactions during cortical negative selection. CCR2 also contributes to cortical DC positioning, as it recruits migratory DCs to perivascular spaces in the cortex to induce deletion against blood-borne antigens $(55,56)$. CCXCKR1 (CCRL1) regulates bioavailability of CCL19, CCL21, and CCL25, but its expression by cTECs and impact on tolerance are currently controversial $(57,58)$. Further investigation is needed to elucidate the contributions of APCs and migratory cues governing cortical negative selection.

\section{Migration of Post-Positive Selection Thymocytes into the Medulla}

The migration of post-positive selection thymocytes into the medulla is critical for the induction of central tolerance. If the medulla does not develop, or thymocytes cannot accumulate therein, negative selection is impaired, and autoimmunity arises (59-64). Only positively selected thymocytes gain access to the medulla (31); recent evidence suggests CXCR4 is responsible for cortical retention of DP cells (65). Following positive selection, thymocytes migrate much more rapidly $(12-16 \mu \mathrm{m} / \mathrm{min}$ postselection versus $6-8 \mu \mathrm{m} / \mathrm{min}$ pre-selection) and undergo chemotaxis toward the medulla $(31,66,67)$. It is commonly assumed that thymocytes enter the medulla at the SP stage. However, plexinD1 deficiency results in relocalization of $\mathrm{CD} 9^{+}$cells from the medulla into the cortex, suggesting post-positive selection $\mathrm{CD}^{+} 9^{+} \mathrm{DP}$ cells may enter the medulla $(32,33)$. Furthermore, the kinetics of medullary entry after positive selection, compared to the timing of differentiation from the DP to SP stage indicates that $\mathrm{CD}^{+}{ }^{+}$DP cells enter the medulla (68). Thus, positive selection likely induces rapid thymocyte medullary entry; further studies are required to determine if and how $\mathrm{CD} 69^{+} \mathrm{DP}$ cells overcome cortical retention to enter the medulla.

The chemokine receptor CCR7 is critical for thymocyte localization in the medulla $(31,51)$. CCR7 is expressed by SP thymocytes $(51,54,69,70)$, while the ligands CCL19 and CCL21 are expressed by mTECs (71). In mice deficient for CCR7 or its ligands, medullary accumulation of SP cells is diminished, negative selection is impaired, and autoimmunity ensues (59, 60). Although CCR7 is required for SP chemotaxis toward the medulla and accumulation therein, $C c r 7^{-1-}$ SP cells enter and migrate within the medulla (31). In contrast, SP medullary entry is abrogated by pertussis toxin $(31,69)$, which blocks signaling through $\mathrm{G \alpha}_{\mathrm{i}}$-associated $\mathrm{G}$ protein coupled receptors (GPCRs), including chemokine receptors. Thus, other GPCRs must contribute to thymocyte medullary localization. We speculate that CCR4 may contribute to medullary entry. CD69+DP and CD69 + CD4SP thymocytes express CCR4 $(54,69)$ and undergo chemotaxis toward the ligands CCL17 and CCL22 (17), which are expressed in the medulla $(18,72)$. CCR4 is up-regulated early after positive selection, while CCR7 is expressed on more mature SP cells (54), suggesting differential roles in guiding thymocytes into the medulla. CCR4 may be responsible for initial medullary entry of post-positive selection cells, while CCR7 may promote retention of maturing SPs (Figure 2). Future studies are required to address the relative contributions of CCR4 and other GPCRs to medullary entry and central tolerance, though a recent study did not identify a role for CCR4 in these processes (54). 


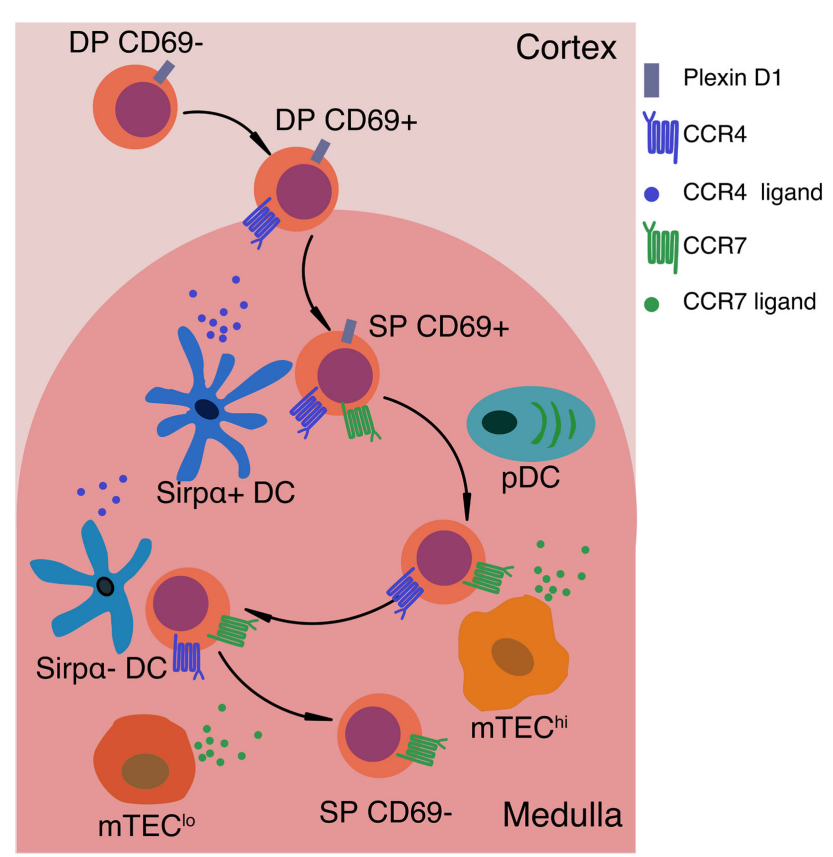

FIGURE 2 | Signals that impact motility and localization of positively selected thymocytes. After positive selection, thymocytes up-regulate CD69 and the chemokine receptor CCR4. CCR4 ligands are expressed by medullary DCs, thus creating a chemotactic gradient that may promote medullary entry of post-positive selection thymocytes. PlexinD1 is expressed on DP and immature SP thymocytes, and may also promote medullary entry by inhibiting responses to cortical chemokines and releasing thymocytes from tight interactions with cTECs. As SP cells mature, they up-regulate CCR7, promoting chemotaxis toward the gradient of $\mathrm{CCR} 7$ ligands produced by $\mathrm{mTEC}^{\mathrm{lo}}\left(\mathrm{CD} 80^{\mathrm{lo}} \mathrm{MHC}-\|^{\mathrm{lo}}\right)$ and $\mathrm{mTEC}^{\text {hi }}\left(\mathrm{CD} 80^{+} \mathrm{MHC}-\|^{\text {hi }}\right)$ cells. CCR7 signaling is critical for maintaining SP thymocytes within the medulla. In the absence of CCR7, SP cells do not undergo efficient negative selection against TRAs. Expression of CCR7 and CCR4 on SP thymocytes may also promote chemokinesis, or rapid motility of SP thymocytes, as well as efficient interactions with the two main subsets of medullary APCs, mTEC ${ }^{\text {hi }}$ cells and DCs, respectively. Thus, chemokine-guided migration likely impacts multiple aspects of SP motility and cellular interactions that are required to ensure SP thymocytes efficiently scan numerous medullary APCs to encounter the full array of self-antigens that induce central tolerance.

\section{APCs Governing Medullary Negative Selection and Treg Generation}

Once SP thymocytes migrate into the medulla, they encounter heterogeneous APCs that enforce self-tolerance (Figure 2). Medullary APCs display peptides derived from a wide array of tissue-restricted antigens (TRAs), proteins otherwise expressed by peripheral tissues. mTEC $^{\text {hi }}$ cells express high levels of CD80 and MHC-II, as well as the transcriptional regulator AIRE, which induces mTEC differentiation and expression of diverse TRAs that were previously epigenetically silenced (73-81). AIRE-dependent expression of such TRAs is essential for the induction of central tolerance in mice and humans (82-87). Medullary DCs also contribute to negative selection; they can be divided into intrathymically derived Sirp $\alpha^{-}$conventional DC (cDC), migratory Sirp $\alpha^{+}$ cDC, and plasmacytoid DCs (pDC) $(88,89)$. Other APCs, such as
B cells, may also contribute to negative selection (90-92), but are not discussed here.

Several experimental models indicate that mTECs can directly present peptide:MHCs to mediate negative selection and Treg induction. Negative selection against model self-antigens was intact following ablation of DCs or MHC-II expression on hematopoietic cells, demonstrating that mTECs can be sufficient to mediate negative selection $(93,94)$. Furthermore, miRNAmediated reduction of MHC-II expression in mTECs resulted in diminished negative selection of TCR transgenic thymocytes to a model TRA, demonstrating that direct antigen presentation by mTECs is required for deletion in some cases (95). Direct presentation of TRAs by mTECs can also induce Treg differentiation (96). While endogenous proteins in mTECs will naturally access the MHC-I processing and presentation pathway, presentation on MHC-II is facilitated by macroautophagy, which is required for central tolerance (97). Thus, mTECs have an intrinsic capacity to present diverse self-antigens to mediate central tolerance of CD4SP and CD8SP cells.

DCs are also critical for thymic central tolerance. DC ablation in a CD11c-DTA model resulted in impaired negative selection and fatal autoimmunity (98). MHC-II ablation on hematopoietic cells impaired both Treg induction and negative selection against serum-borne and soluble TRAs (99-101). Sirp $\alpha^{+} \mathrm{cDC}$ and pDC can acquire peripheral antigens and traffic them to the thymus to induce negative selection $(102,103)$. Also, in some models of mTEC-expressed TRAs, DCs isolated from the thymus stimulate TRA-specific T cells specific more efficiently than mTECs themselves, indicating that antigens are transferred efficiently from mTECs to DCs to mediate deletion (104). Transfer of model TRAs from mTECs to DCs can be AIRE-dependent and required for negative selection $(99,104)$. The mechanisms of antigen transfer between mTECs and DCs remain to be elucidated. mTECs may secrete or release antigen in vesicles; DCs may acquire antigen by endocytosis of apoptotic mTECs (105); or peptide:MHC complexes may be acquired by DCs from mTEC cell membranes $(104,106)$. Thus, the heterogeneous thymic DC compartment promotes central tolerance against peripheral, blood-borne, and mTEC-derived self-antigens.

While both mTECs and DCs induce tolerance to some antigens, their relative contributions to central tolerance of polyclonal thymocytes have been difficult to ascertain. Using TCR repertoire analysis of Treg and naïve T cells, Perry et al. recently compared the impact of restricting antigen presentation to DCs versus mTECs (107). mTECs and DCs mediated negative selection of non-overlapping TCRs, and DCs deleted about threefold more TCRs. These findings are in keeping with studies showing that both subsets are important for negative selection. Furthermore, both mTECs and DCs induced Treg differentiation. AIRE was critical for negative selection and Treg induction of lower frequency TCRs, and the Sirp $\alpha^{-}$subset of $\mathrm{CDC}$ was required for AIREdependent Treg generation (107). Importantly, this study compared the effects of diminished MHC-II expression on mTECs with ablated MHC-II expression on DCs, and may thus underestimate the relative contribution of mTECs to central tolerance. Nonetheless, it is clear that complete central tolerance will require efficient thymocyte interactions with both mTECs and DCs. 


\section{Migratory Cues Promoting Medullary Central Tolerance}

Given that DCs acquire TRAs from mTECs, it is likely DCs must localize near mTECs to mediate efficient central tolerance. Consistent with this, XCR1, which is expressed on Sirp $\alpha^{-} \mathrm{cDC}$, was required for localization of $\mathrm{CDC}$ to the center of the medulla (53). In $\mathrm{Xcl1}^{-/-}$mice, Treg cellularity was diminished, the TCR repertoire was altered, and autoimmune manifestations occurred, indicating that medullary localization of Sirp $\alpha^{-}$cDC is required for central tolerance (53). This suggests a model in which XCR1 promotes direct apposition of Sirp $\alpha^{-}$DCs with mTECs for TRA acquisition. Sirp $\alpha^{+}$cDC and pDC, which carry peripheral antigens into the medulla, migrate into the thymus through vasculature in a P-selectin, VLA4, and GPCR-dependent manner (103). CCR9 is required for thymic entry of pDC, but the corresponding GPCR for Sirp $\alpha^{+} \mathrm{cDC}$ has not been identified (102). Although thymic DCs express CCR7 and migrate toward CCR7 ligands, Ccr $7^{-1-}$ DCs localize properly within the medulla (53). Thus, signals required for medullary localization of Sirp $\alpha^{+}$DCs and pDCs remain to be identified.

SP thymocytes were recently estimated to have a medullary residence time of $\sim 4-5$ days (108), shorter than the previous estimate of $\sim 12$ days (109), and each AIRE-dependent TRA is expressed on only $1-3 \%$ of $\operatorname{AIRE}^{+}$mTEC $^{\text {hi }}$ cells $(74,110)$. Thus, thymocytes must rapidly scan multiple mTECs and DCs to encounter the full spectrum of medullary self-antigens that promote central tolerance. Chemokines can promote lymphocyte chemokinesis (111), and CCR7 has been shown to promote rapid motility of SP thymocytes (31). Fast SP migration is also dependent on MST1, which promotes integrinmediated binding of SP thymocytes to ICAM1 in the context of CCL21 (112). It remains to be determined whether other chemokine signals are required for rapid motility of SP thymocytes.

It remains to be established whether interactions between thymocytes and medullary APCs are driven by chemotaxis toward APCs or random encounters due to fast SP motility. Several studies suggest chemokines may facilitate T cell:APC interactions in secondary lymphoid organs. Using microspheres releasing CCL19 and CCL21, a recent study demonstrated that when sources of CCR7 ligands were interspersed, T cells hopped between microspheres, potentially facilitating antigen sampling (113). Both CCR4 and CCR7 have been implicated in promoting $\mathrm{T}$ cell:APC interactions that drive naïve $\mathrm{T}$ cell activation

\section{References}

1. Petrie HT, Zuniga-Pflucker J-C. Zoned out: functional mapping stromal signaling microenvironments in the thymus. Annu Rev Immunol (2007) 25:649-79. doi:10.1146/annurev.immunol.23.021704.115715

2. Love PE, Bhandoola A. Signal integration and crosstalk during thymocyte migration and emigration. Nat Rev Immunol (2011) 11:469-77. doi:10.1038/ nri2989

3. Lind EF, Prockop SE, Porritt HE, Petrie HT. Mapping precursor movement through the postnatal thymus reveals specific microenvironments supporting
$(114,115)$. Thus, CCR4 and CCR7 may also promote cellular interactions between SP cells and DCs and mTECs, respectively. Indeed, Mst1 was required for efficient interactions between SP cells undergoing negative selection and Aire ${ }^{+}$mTECs expressing a model TRA (112), suggesting that CCR7 may enhance adhesion between SP cells and mTECs via intergrin:ICAM1 interactions. Furthermore, CCR7 deficiency was recently shown to result in increased Treg cellularity (54), which may also reflect the contribution of CCR7 to avid APC interactions. Although the basis for the decision to undergo apoptosis versus Treg specification is not resolved, current models favor an avidity model in which the highest avidity TCR signals promote negative selection, while a range of slightly lower avidity signals promote Treg induction as well as negative selection $(116,117)$. Thus, if CCR7 promotes T cell:APC interactions, CCR7 deficiency might result in lower avidity interactions that favor Treg induction. The fact that CCR7 ligands are expressed by mTECs, while CCR4 ligands are expressed by DCs also raises the possibility that CCR7 and CCR4 promote interactions with mTECs and DCs, respectively (Figure 2). Further investigation will be required to elucidate the contribution of chemokines or other adhesion molecules to interactions with medullary APCs driving central tolerance.

\section{Areas for Future Investigation}

Chemokine receptors and integrins promote migration and adhesion required for thymocyte:stromal interactions that drive $\mathrm{T}$ cell differentiation and selection. However, multiple localization and migration cues remain to be elucidated. We have not identified signals driving localization of DN3 thymocytes to the sub-capsule, accumulation of pre-selection DP cells near the medulla, or thymocyte:APC interactions during cortical negative selection. The identities of GPCRs other than CCR7 that promote medullary entry and APC interactions remain to be determined. We are just beginning to appreciate that localization of stromal cells is critical for thymocyte differentiation, and future studies will likely identify factors driving proper stromal organization. Thus, many open questions remain regarding the localization and adhesion cues that promote differentiation of a fully functional and self-tolerant T cell compartment.

\section{Acknowledgments}

This work was supported by National Institutes of Health grant R01 AI104870 to LE.

defined stages of early lymphoid development. J Exp Med (2001) 194:127-34 doi:10.1084/jem.194.2.127

4. Porritt HE, Gordon K, Petrie HT. Kinetics of steady-state differentiation and mapping of intrathymic-signaling environments by stem cell transplantation in nonirradiated mice. J Exp Med (2003) 198:957-62. doi:10.1084/jem. 20030837

5. Serwold T, Ehrlich LI, Weissman IL. Reductive isolation from bone marrow and blood implicates common lymphoid progenitors as the major source of thymopoiesis. Blood (2009) 113:807-15. doi:10.1182/blood-2008-08173682 
6. Schlenner SM, Madan V, Busch K, Tietz A, Laufle C, Costa C, et al. Fate mapping reveals separate origins of $\mathrm{T}$ cells and myeloid lineages in the thymus. Immunity (2010) 32:426-36. doi:10.1016/j.immuni.2010.03.005

7. Ehrlich LIR, Serwold T, Weissman IL. In vitro assays misrepresent in vivo lineage potentials of murine lymphoid progenitors. Blood (2011) 117:2618-24. doi:10.1182/blood-2010-05-287102

8. Scimone ML, Aifantis I, Apostolou I, Boehmer HV, Andrian UHV. A multistep adhesion cascade for lymphoid progenitor cell homing to the thymus. Proc Natl Acad Sci U S A (2006) 103:7006-11. doi:10.1073/pnas. 0602024103

9. Rossi FM, Corbel SY, Merzaban JS, Carlow DA, Gossens K, Duenas J, et al. Recruitment of adult thymic progenitors is regulated by P-selectin and its ligand PSGL-1. Nat Immunol (2005) 6:626-34. doi:10.1038/ni1203

10. Krueger A, Willenzon S, Lyszkiewicz M, Kremmer E, Forster R. CC chemokine receptor 7 and 9 double-deficient hematopoietic progenitors are severely impaired in seeding the adult thymus. Blood (2010) 115:1906-12. doi:10.1182/ blood-2009-07-235721

11. Zlotoff DA, Sambandam A, Logan TD, Bell JJ, Schwarz BA, Bhandoola A. CCR7 and CCR9 together recruit hematopoietic progenitors to the adult thymus. Blood (2010) 115:1897-905. doi:10.1182/blood-2009-08-237784

12. Uehara S, Grinberg A, Farber JM, Love PE. A role for CCR9 in T lymphocyte development and migration. J Immunol (2002) 168:2811-9. doi:10.4049/ jimmunol.168.6.2811

13. Shah DK, Zuniga-Pflucker JC. An overview of the intrathymic intricacies of T cell development. J Immunol (2014) 192:4017-23. doi:10.4049/jimmunol. 1302259

14. Rothenberg EV. T cell lineage commitment: identity and renunciation. J Immunol (2011) 186:6649-55. doi:10.4049/jimmunol.1003703

15. Yuan JS, Kousis PC, Suliman S, Visan I, Guidos CJ. Functions of Notch signaling in the immune system: consensus and controversies. Annu Rev Immunol (2010) 28:343-65. doi:10.1146/annurev.immunol.021908.132719

16. Kim CH, Pelus LM, White JR, Broxmeyer HE. Differential chemotactic behavior of developing $\mathrm{T}$ cells in response to thymic chemokines. Blood (1998) 91:4434-43.

17. Campbell JJ, Pan J, Butcher EC. Cutting edge: developmental switches in chemokine responses during T cell maturation. J Immunol (1999) 163:2353-7.

18. Bleul CC, Boehm T. Chemokines define distinct microenvironments in the developing thymus. Eur J Immunol (2000) 30:3371-9. doi:10.1002/15214141(2000012)30:12<3371::AID-IMMU3371>3.0.CO;2-L

19. Ki S, Park D, Selden HJ, Seita J, Chung H, Kim J, et al. Global transcriptional profiling reveals distinct functions of thymic stromal subsets and age-related changes during thymic involution. Cell Rep (2014) 9:402-15. doi:10.1016/j. celrep.2014.08.070

20. Plotkin J, Prockop SE, Lepique A, Petrie HT. Critical role for CXCR4 signaling in progenitor localization and $\mathrm{T}$ cell differentiation in the postnatal thymus. $J$ Immunol (2003) 171:4521-7. doi:10.4049/jimmunol.171.9.4521

21. Salomon DR, Crisa L, Mojcik CF, Ishii JK, Klier G, Shevach EM. Vascular cell adhesion molecule-1 is expressed by cortical thymic epithelial cells and mediates thymocyte adhesion. Implications for the function of alpha4beta1 (VLA4) integrin in T-cell development. Blood (1997) 89: 2461-71.

22. Prockop SE, Palencia S, Ryan CM, Gordon K, Gray D, Petrie HT. Stromal cells provide the matrix for migration of early lymphoid progenitors through the thymic cortex. J Immunol (2002) 169:4354-61. doi:10.4049/jimmunol.169.8. 4354

23. Ara T, Itoi M, Kawabata K, Egawa T, Tokoyoda K, Sugiyama T, et al. A role of CXC chemokine ligand 12/stromal cell-derived factor-1/pre-B cell growth stimulating factor and its receptor CXCR4 in fetal and adult T cell development in vivo. J Immunol (2003) 170:4649-55. doi:10.4049/jimmunol.170.9.4649

24. Trampont PC, Tosello-Trampont AC, Shen Y, Duley AK, Sutherland AE, Bender TP, et al. CXCR4 acts as a costimulator during thymic beta-selection. Nat Immunol (2010) 11:162-70. doi:10.1038/ni.1830

25. Ciofani M, Schmitt TM, Ciofani A, Michie AM, Cuburu N, Aublin A, et al. Obligatory role for cooperative signaling by pre-TCR and Notch during thymocyte differentiation. J Immunol (2004) 172:5230-9. doi:10.4049/jimmunol. 172.9.5230

26. Boudil A, Matei IR, Shih HY, Bogdanoski G, Yuan JS, Chang SG, et al. IL7 coordinates proliferation, differentiation and Tcra recombination during thymocyte beta-selection. Nat Immunol (2015) 16:397-405. doi:10.1038/ni. 3122

27. Wurbel MA, Malissen B, Campbell JJ. Complex regulation of CCR9 at multiple discrete stages of T cell development. Eur J Immunol (2006) 36:73-81. doi:10. 1002/eji.200535203

28. Uehara S, Hayes SM, Li L, El-Khoury D, Canelles M, Fowlkes BJ, et al. Premature expression of chemokine receptor CCR9 impairs T cell development. J Immunol (2006) 176:75-84. doi:10.4049/jimmunol.176.1.75

29. Benz C, Heinzel K, Bleul CC. Homing of immature thymocytes to the subcapsular microenvironment within the thymus is not an absolute requirement for T cell development. Eur J Immunol (2004) 34:3652-63. doi:10.1002/eji. 200425248

30. Misslitz A, Pabst O, Hintzen G, Ohl L, Kremmer E, Petrie HT, et al. Thymic $\mathrm{T}$ cell development and progenitor localization depend of CCR7. J Exp Med (2004) 200:481-91. doi:10.1084/jem.20040383

31. Ehrlich LIR, Oh DY, Weissman IL, Lewis RS. Differential contribution of chemotaxis and substrate restriction to segregation of immature and mature thymocytes. Immunity (2009) 31:986-98. doi:10.1016/j.immuni.2009.09.020

32. Choi YI, Duke-Cohan JS, Ahmed WB, Handley MA, Mann F, Epstein JA, et al. PlexinD1 glycoprotein controls migration of positively selected thymocytes into the medulla. Immunity (2008) 29:888-98. doi:10.1016/j.immuni. 2008.10.008

33. Choi YI, Duke-Cohan JS, Tan J, Gui J, Singh MK, Epstein JA, et al. Plxnd1 expression in thymocytes regulates their intrathymic migration while that in thymic endothelium impacts medullary topology. Front Immunol (2013) 4:392. doi:10.3389/fimmu.2013.00392

34. Choi YI, Duke-Cohan JS, Chen W, Liu B, Rossy J, Tabrin T, et al. Dynamic control of betal integrin adhesion by the plexinD1-sema3E axis. Proc Natl Acad Sci U S A (2014) 111:379-84. doi:10.1073/pnas.1314209111

35. Petrie HT. Cell migration and the control of post-natal T-cell lymphopoiesis in the thymus. Nat Rev Immunol (2003) 3:859-66. doi:10.1038/nri1223

36. Phee H, Dzhagalov I, Mollenauer M, Wang Y, Irvine DJ, Robey E, et al. Regulation of thymocyte positive selection and motility by GIT2. Nat Immunol (2010) 503:503-11. doi:10.1038/ni.1868

37. Stritesky G, Xing Y, Erickson JR, Kalekar LA, Wang X, Mueller DL, et al. Murine thymic selection quantified using a unique method to capture deleted T cells. Proc Natl Acad Sci U S A (2013) 110:4679-84. doi:10.1073/pnas. 1217532110

38. Sawicka M, Stritesky GL, Reynolds J, Abourashchi N, Lythe G, Molina-Paris C, et al. From pre-DP, post-DP, SP4, and SP8 thymocyte cell counts to a dynamical model of cortical and medullary selection. Front Immunol (2014) 5:19. doi:10.3389/fimmu.2014.00019

39. Daley SR, Hu DY, Goodnow CC. Helios marks strongly autoreactive CD4+ T cells in two major waves of thymic deletion distinguished by induction of PD-1 or NF-kB. J Exp Med (2013) 210:269-85. doi:10.1084/jem.20121458

40. Takahama Y, Takada K, Murata S, Tanaka K. b5t-containing thymoproteasome: specific expression in thymic cortical epithelial cells and role in positive selection of CD8+ T cells. Curr Opin Immunol (2012) 24:92-8. doi:10.1016/j. coi.2012.01.006

41. Bonomo A, Matzinger P. Thymus epithelium induces tissue-specific tolerance. J Exp Med (1993) 177:1153-64. doi:10.1084/jem.177.4.1153

42. Carlow DA, Teh S-J, Teh H-S. Altered thymocyte development resulting from expressing a deleting ligand on selecting thymic epithelium. J Immunol (1992) 148:2988-95.

43. Hoffman MW, Heath WR, Ruschmeyer D, Miller JFAP. Deletion of highavidity T cells by thymic epithelium. Proc Natl Acad Sci U S A (1992) 92:9851-9. doi:10.1073/pnas.92.21.9851

44. Jordan RK, Robinson JH, Hopkinson NA, House KC, Bentley AL. Thymic epithelium and the induction of transplantation tolerance in nude mice. Nature (1985) 314:454-6. doi:10.1038/314454a0

45. Modigliani Y, Thomas-Vaslin V, Bandeira A, Coltey M, Douarin NML, Coutinho A, et al. Lymphocytes selected in allogeneic thymic epithelium mediate dominant tolerance toward tissue grafts of the thymic epithelium haplotype. Proc Natl Acad Sci U S A (1995) 92:7555-9. doi:10.1073/pnas.92. 16.7555

46. Capone M, Romagnani P, Beermann F, MacDonald HR, van Meerwijk JP. Dissociation of thymic positive and negative selection in transgenic mice expressing major histocompatibility complex class I molecules exclusively on 
thymic cortical epithelial cells. Blood (2001) 97:1336-43. doi:10.1182/blood. V97.5.1336

47. Laufer TM, DeKoning J, Markowitz JS, Lo D, Glimcher LH. Unopposed positive selection and autoreactivity in mice expressing class II MHC only on thymic cortex. Nature (1996) 383:81-5. doi:10.1038/383081a0

48. Mayerova D, Hogquist KA. Central tolerance to self-antigen expressed by cortical epithelial cells. J Immunol (2003) 172:851-6. doi:10.4049/jimmunol. 172.2 .851

49. McCaughtry TM, Baldwin TA, Wilken MS, Hogquist KA. Clonal deletion of thymocytes can occur in the cortex with no involvement of the medulla. J Exp Med (2008) 205:2575-84. doi:10.1084/jem.20080866

50. Gray DHD, Seach N, Ueno T, Milton MK, Liston A, Lew AM, et al. Developmental kinetics, turnover, and stimulatory capacity of thymic epithelial cells. Blood (2006) 108:3777-85. doi:10.1182/blood-2006-02-004531

51. Ueno T, Saito F, Gray DHD, Kuse S, Hieshima K, Nakano H, et al. CCR7 signals are essential for cortex-medulla migration of developing thymocytes. J Exp Med (2004) 200:493-505. doi:10.1084/jem.20040643

52. Ladi E, Schwickert TA, Chtanova T, Chen Y, Herzmark P, Yin X, et al. Thymocyte-dendritic cell interactions near sources of CCR7 ligands in the thymic cortex. J Immunol (2008) 181:7014-23. doi:10.4049/jimmunol.181.10. 7014

53. Lei Y, Ripen AM, Ishimaru N, Ohigashi I, Nagasawa T, Jeker LT, et al. Airedependent production of XCL1 mediates medullary accumulation of thymic dendritic cells and contributes to regulatory T cell development. J Exp Med (2011) 208:383-94. doi:10.1084/jem.20102327

54. Cowan JE, McCarthy NI, Parnell SM, White AJ, Bacon A, Serge A, et al. Differential requirement for CCR4 and CCR7 during the development of innate and adaptive alpha beta $\mathrm{T}$ cells in the adult thymus. J Immunol (2014) 193:1204-12. doi:10.4049/jimmunol.1400993

55. Baba T, Nakamoto Y, Mukaida N. Crucial contribution of thymic Sirpa+ conventional dendritic cells to central tolerance against blood-borne antigens in a CCR2-dependent manner. J Immunol (2009) 183:3053-63. doi:10.4049/ jimmunol.0900438

56. Cedile O, Lobner M, Toft-Hansen H, Frank I, Wlodarczyk A, Irla M, et al. Thymic CCL2 influences induction of T-cell tolerance. J Autoimmun (2014) 55:73-85. doi:10.1016/j.jaut.2014.07.004

57. Bunting MD, Comerford I, Seach N, Hammett MV, Asquith DL, Korner $\mathrm{H}$, et al. CCX-CKR deficiency alters thymic stroma impairing thymocyte development and promoting autoimmunity. Blood (2012) 121:118-28. doi:10. 1182/blood-2012-06-434886

58. Lucas B, White AJ, Ulvmar MH, Nibbs RJB, Sitnik KM, Agace WW, et al. CCRL1/ACKR4 is expressed in key thymic microenvironments but is dispensable for T lymphopoiesis at steady state in adult mice. Eur J Immunol (2015) 45:574-83. doi:10.1002/eji.201445015

59. Kurobe H, Liu C, Ueno T, Saito F, Ohigashi I, Seach N, et al. CCR7-dependent cortex-to-medulla migration of positively selected thymocytes is essential for establishing central tolerance. Immunity (2006) 24:165-77. doi:10.1016/j. immuni.2005.12.011

60. Nitta T, Nitta S, Lei Y, Lipp M, Takahama Y. CCR7-mediated migration of developing thymocytes to the medulla is essential for negative selection to tissue-restricted antigens. Proc Natl Acad Sci U S A (2009) 106:17129-33. doi:10.1073/pnas.0906956106

61. Bonito AJ, Aloman C, Fiel MI, Danzl NM, Cha S, Weinstein EG, et al. Medullary thymic epithelial cell depletion leads to autoimmune hepatitis. $J$ Clin Investig (2013) 123:3510-24. doi:10.1172/JCI65414

62. Burkly L, Hession C, Ogata L, Reilly C, Marconi LA, Olson D, et al. Expression of relB is required for the development of thymic medulla and dendritic cells. Nature (1995) 373:531-6. doi:10.1038/373531a0

63. Lomada D, Liu B, Coghlan L, Hu Y, Richie ER. Thymus medulla formation and central tolerance are restored in IKKalpha-/- mice that express an IKKalpha transgene in keratin 5+ thymic epithelial cells. J Immunol (2007) 178:829-37. doi:10.4049/jimmunol.178.2.829

64. Jenkinson SR, Williams JA, Jeon H, Zhang J, Nitta T, Ohigashi I, et al. TRAF3 enforces the requirement for $\mathrm{T}$ cell cross-talk in thymic medullary epithelial development. Proc Natl Acad Sci U S A (2013) 110:21107-12. doi:10.1073/ pnas. 1314859111

65. Halkias J, Melichar HJ, Taylor KT, Ross JO, Yen B, Cooper SB, et al. Opposing chemokine gradients control human thymocyte migration in situ. J Clin Investig (2013) 123:2131-42. doi:10.1172/JCI67175
66. LeBorgne M, Ladi E, Dzhagalov I, Herzmark P, Liao YF, Chakraborty AK, et al. The impact of negative selection on thymocytes migration in the medulla. Nat Immunol (2009) 823:823-30. doi:10.1038/ni.1761

67. Witt CM, Raychaudhuri S, Scaefer B, Chakraborty AK, Robey EA. Directed migration of positively selected thymocytes visualized in real time. PLoS Biol (2005) 3:e160. doi:10.1371/journal.pbio.0030373

68. Ross JO, Melichar HJ, Au-Yeung BB, Herzmark P, Weiss A, Robey EA. Distinct phases in the positive selection of CD8+ T cells distinguished by intrathymic migration and T-cell receptor signaling patterns. Proc Natl Acad Sci U S A (2014) 111:E2550-8. doi:10.1073/pnas.1408482111

69. Suzuki G, Sawa H, Kobayashi Y, Nakata Y, Nakagawa K-I, Uzawa A, et al. Pertussis toxin-sensitive signal controls the trafficking of thymocytes across the corticomedullary junction in the thymus. J Immunol (1999) 162:5981-5.

70. Davalos-Misslitz AC, Worbs T, Willenzon S, Bernhardt G, Forster R. Impaired responsiveness to $\mathrm{T}$-cell receptor stimulation and defective negative selection of thymocytes in CCR7-deficient mice. Blood (2007) 110:4351-9. doi:10.1182/ blood-2007-01-070284

71. Lkhagvasuren E, Sakata M, Ohigashi I, Takahama Y. Lymphotoxin beta receptor regulates the development of CCL21-expressing subset of postnatal medullary thymic epithelial cells. J Immunol (2013) 190:5110-7. doi:10.4049/ jimmunol.1203203

72. Alferink J, Lieberam I, Reindl W, Behrens A, Weiss S, Huser N, et al. Compartmentalized production of CCL17 in vivo: strong inducibility in peripheral dendritic cells contrasts selective absence from the spleen. J Exp Med (2003) 197:585-99. doi:10.1084/jem.20021859

73. Derbinski J, Schulte A, Kyewski B, Klein L. Promiscuous gene expression in medullary thymic epithelial cells mirrors the peripheral self. Nat Immunol (2001) 2:1032-9. doi:10.1038/ni723

74. Sansom SN, Shikama-Dorn N, Zhanybekova S, Nusspaumer G, Macaulay IC, Deadman ME, et al. Population and single-cell genomics reveal the Aire dependency, relief from Polycomb silencing, and distribution of self-antigen expression in thymic epithelia. Genome Res (2014) 24:1918-31. doi:10.1101/ gr. 171645.113

75. Derbinski J, Gabler J, Brors B, Tierling S, Jonnakuty S, Hergenhahn M, et al. Promiscuous gene expression in thymic epithelial cells is regulated at multiple levels. J Exp Med (2005) 202:33-45. doi:10.1084/jem.20050471

76. Nishikawa Y, Hirota F, Yano M, Kitajima H, Miyazaki J, Kawamoto H, et al. Biphasic Aire expression in early embryos and in medullary thymic epithelial cells before end-stage terminal differentiation. J Exp Med (2010) 207:963-71. doi:10.1084/jem.20092144

77. Yano M, Kuroda N, Han H, Meguro-Horike M, Nishikawa Y, Kiyonari H, et al. Aire controls the differentiation program of thymic epithelial cells in the medulla for the establishment of self-tolerance. J Exp Med (2008) 205:2827-38. doi:10.1084/jem.20080046

78. Dooley J, Erickson M, Farr AG. Alterations of the medullary epithelial compartment in the Aire-deficient thymus: implications for programs of thymic epithelial differentiation. J Immunol (2008) 181:5225-32. doi:10.4049/ jimmunol.181.8.5225

79. Anderson MS, Venanzi ES, Chen Z, Berzins SP, Benoist C, Mathis D. The cellular mechanism of Aire control of $\mathrm{T}$ cell tolerance. Immunity (2005) 23:227-39. doi:10.1016/j.immuni.2005.07.005

80. Metzger TC, Khan IS, Gardner JM, Mouchess ML, Johannes KP, Krawisz AK, et al. Lineage tracing and cell ablation identify a post-Aire-expressing thymic epithelial cell population. Cell Rep (2013) 5:166-79. doi:10.1016/j.celrep.2013. 08.038

81. Koh AS, Kuo AJ, Park SY, Cheung P, Abramson J, Bua D, et al. Aire employs a histone-binding module to mediate immunological tolerance, linking chromatin regulation with organ-specific autoimmunity. Proc Natl Acad Sci U S A (2008) 105:15878-83. doi:10.1073/pnas.0808470105

82. Liston A, Lesage S, Wilson J, Peltonen L, Goodnow CC. Aire regulates negative selection of organ-specific T cells. Nat Immunol (2003) 4:350-4. doi:10.1038/ ni906

83. Liston A, Gray DH, Lesage S, Fletcher AL, Wilson J, Webster KE, et al. Gene dosage - limiting role of Aire in thymic expression, clonal deletion, and organ-specific autoimmunity. J Exp Med (2004) 200:1015-26. doi:10.1084/ jem.20040581

84. Nagamine K, Peterson P, Scott HS, Kudoh J, Minoshima S, Heino M, et al. Positional cloning of the APECED gene. Nat Genet (1997) 17:393-8. doi:10. 1038/ng1297-393 
85. DeVoss J, Hou Y, Johannes K, Lu W, Liou GI, Rinn J, et al. Spontaneous autoimmunity prevented by thymic expression of a single self-antigen. J Exp Med (2006) 203:2727-35. doi:10.1084/jem.20061864

86. Anderson MS, Venanzi ES, Klein L, Chen Z, Berzins SP, Turley S, et al. Projection of an immunological self shadow within the thymus by the Aire protein. Science (2002) 298:1395-401. doi:10.1126/science.1075958

87. Finnish-German APECED Consortium. An autoimmune disease, APECED, caused by mutations in a novel gene featuring two PHD-type zinc-finger domains. Nat Genet (1997) 17:399-403. doi:10.1038/ng1297-399

88. Wu L, Shortman K. Heterogeneity of thymic dendritic cells. Semin Immunol (2005) 17:304-12. doi:10.1016/j.smim.2005.05.001

89. Li J, Park J, Foss D, Goldschneider I. Thymus-homing peripheral dendritic cells constitute two of the three major subsets of dendritic cells in the steadystate thymus. J Exp Med (2009) 206:607-22. doi:10.1084/jem.20082232

90. Frommer F, Waisman A. B cells participate in thymic negative selection of murine autoreactive CD4+ T cells. PLoS One (2010) 5:e15372. doi:10.1371/ journal.pone. 0015372

91. Perera J, Meng L, Meng F, Huang H. Autoreactive thymic B cells are efficient antigen-presenting cells of cognate self-antigens for $\mathrm{T}$ cell negative selection. Proc Natl Acad Sci U S A (2013) 110:17011-6. doi:10.1073/pnas.1313001110

92. Yamano T, Nedjic J, Hinterberger M, Steinert M, Koser S, Pinto S, et al. Thymic B cells are licensed to present self antigens for central T cell tolerance induction. Immunity (2015) 42:1-15. doi:10.1016/j.immuni.2015.05.013

93. Birnberg T, Bar-On L, Sapoznikov A, Caton ML, Cervantes-Barragan L, Makia $\mathrm{D}$, et al. Lack of conventional dendritic cells is compatible with normal development and $\mathrm{T}$ cell homeostasis, but causes myeloid proliferative syndrome. Immunity (2008) 29:986-97. doi:10.1016/j.immuni.2008.10.012

94. Gallegos AM, Bevan MJ. Central tolerance to tissue-specific antigens mediated by direct and indirect antigen presentation. J Exp Med (2004) 200:1039-49. doi: $10.1084 /$ jem. 20041457

95. Hinterberger M, Aichinger M, Costa OPD, Voehringer D, Hoffman R, Klein L. Autonomous role of medullary thymic epithelial cells in central CD4+ T cell tolerance. Nat Immunol (2010) 11:512-9. doi:10.1038/ni.1874

96. Aschenbrenner K, D’Cruz LM, Vollmann EH, Hinterberger M, Emmerich J, Swee LK, et al. Selection of Foxp3+ regulatory $\mathrm{T}$ cells specific for self antigen expressed and presented by Aire+ medullary thymic epithelial cells. Nat Immunol (2007) 8:351-8. doi:10.1038/ni1444

97. Aichinger M, Wu C, Nedjic J, Klein L. Macroautophagy substrates are loaded onto MHC class II of medullary thymic epithelial cells for central tolerance. $J$ Exp Med (2013) 210:287-300. doi:10.1084/jem.20122149

98. Ohnmacht C, Pullner A, King SBS, Drexler I, Meier S, Brocker T, et al. Constitutive ablation of dendritic cells breaks self-tolerance of CD4 T cells and results in spontaneous fatal autoimmunity. J Exp Med (2009) 206:549-59. doi:10.1084/jem.20082394

99. Hubert F-X, Kinkel SA, Davey GM, Phipson B, Mueller SN, Liston A, et al. Aire regulates the transfer of antigen from mTECs to dendritic cells for induction of thymic tolerance. Blood (2011) 118:2462-72. doi:10.1182/blood-2010-06286393

100. Klein L, Roettinger B, Kyewski B. Sampling of complementing self-antigen pools by thymic stromal cells maximizes the scope of central $\mathrm{T}$ cell tolerance. Eur JImmunol (2001) 31:2476-86. doi:10.1002/1521-4141(200108)31:8<2476: :AID-IMMU2476>3.0.CO;2-T

101. Proietto AI, Dommelen SV, Zhou P, Rizzitelli A, D'Amico A, Steptoe RJ, et al. Dendritic cells in the thymus contribute to T-regulatory cell induction. Proc Natl Acad Sci U S A (2008) 105:19869-74. doi:10.1073/pnas.0810268105

102. Hadeiba H, Lahl K, Edalati A, Oderup C, Habtezion A, Pachynski R, et al. Plasmacytoid dendritic cells transport peripheral antigens to the thymus to promote central tolerance. Immunity (2012) 36:438-50. doi:10.1016/j.immuni. 2012.01.017
103. Bonasio R, Scimone ML, Schaerli P, Grabie N, Lichtman AH, Andrian UHV. Clonal deletion of thymocytes by circulating cells homing to the thymus. Nat Immunol (2006) 7:1092-100. doi:10.1038/ni1106-1234b

104. Koble C, Kyewski B. The thymic medulla: a unique microenvironment for intercellular self-antigen transfer. J Exp Med (2009) 206:1505-13. doi:10.1084/ jem.20082449

105. Gray D, Abramson J, Benoist C, Mathis D. Proliferative arrest and rapid turnover of thymic epithelial cells expressing Aire. J Exp Med (2007) 204:2521-8. doi:10.1084/jem.20070795

106. Millet V, Naquet P, Guinamard RR. Intercellular MHC transfer between thymic epithelial dendritic cells. Eur J Immunol (2008) 38:1257-63. doi:10. 1002/eji.200737982

107. Perry JSA, Lio C-WJ, Kau AL, Nutsch K, Yang Z, Gordon JI, et al. Distinct contributions of Aire and antigen-presenting cell subsets to the generation of self-tolerance in the thymus. Immunity (2014) 41:414-26. doi:10.1016/j. immuni.2014.08.007

108. McCaughtry TM, Wilken MS, Hogquist KA. Thymic emigration revisited. J Exp Med (2007) 204:2513-20. doi:10.1084/jem.20070601

109. Egerton M, Scollay R, Shortman K. Kinetics of mature T-cell development in the thymus. Proc Natl Acad Sci U S A (1990) 87:2579-82. doi:10.1073/pnas.87. 7.2579

110. Derbinski J, Pinto S, Rosch S, Hexel K, Kyewski B. Promiscuous gene expression patterns in single medullary thymic epithelial cells argue for a stochastic mechanism. Proc Natl Acad Sci U S A (2008) 105:657-62. doi:10.1073/pnas. 0707486105

111. Stachowiak AN, Wang Y, Huang YC, Irvine DJ. Homeostatic lymphoid chemokines synergize with adhesion ligands to trigger $\mathrm{T}$ and $\mathrm{B}$ lymphocyte chemokinesis. J Immunol (2006) 177:2340-8. doi:10.4049/jimmunol.177.4. 2340

112. Ueda Y, Katagiri K, Tomiyama T, Yasuda K, Habiro K, Katakai T, et al. Mst1 regulates integrin-dependent thymocyte trafficking and antigen recognition in the thymus. Nat Commun (2012) 3:1098-113. doi:10.1038/ncomms2105

113. Wang Y, Irvine DJ. Convolution of chemoattractant secretion rate, source density, and receptor desensitization direct diverse migration patterns in leukocytes. Integr Biol (2013) 5:481-94. doi:10.1039/c3ib20249f

114. Tang HL, Cyster JG. Chemokine up-regulation and activated T cell attraction by maturing dendritic cells. Science (1999) 284:819-22. doi:10.1126/science. 284.5415.819

115. Friedman RS, Jacobelli J, Krummel MF. Surface-bound chemokines capture and prime T cells for synapse formation. Nat Immunol (2006) 7:1101-8. doi: 10.1038/ni1106-1234a

116. Klein L, Kyewski B, Allen PM, Hogquist KA. Positive and negative selection of the T cell repertoire: what thymocytes see (and don't see). Nat Rev Immunol (2014) 14:377-91. doi:10.1038/nri3667

117. Lee HM, Bautista JL, Scott-Browne J, Mohan JF, Hsieh CS. A broad range of self-reactivity drives thymic regulatory $\mathrm{T}$ cell selection to limit responses to self. Immunity (2012) 37:475-86. doi:10.1016/j.immuni.2012.07.009

Conflict of Interest Statement: The authors declare that the research was conducted in the absence of any commercial or financial relationships that could be construed as a potential conflict of interest.

Copyright (c) $2015 \mathrm{Hu}$, Lancaster and Ehrlich. This is an open-access article distributed under the terms of the Creative Commons Attribution License (CC BY). The use, distribution or reproduction in other forums is permitted, provided the original author(s) or licensor are credited and that the original publication in this journal is cited, in accordance with accepted academic practice. No use, distribution or reproduction is permitted which does not comply with these terms. 